Pacific Journal of Mathematics

APPROXIMATING COMPACT SETS IN NORMED LINEAR 


\title{
APPROXIMATING COMPACT SETS IN NORMED LINEAR SPACES
}

\author{
JACK GIROLO
}

\begin{abstract}
It is shown that in normed linear spaces compact sets can be approximated by compact absolute neighborhood retracts in the following sense: If $X$ is a compact subset of a normed linear space, then for every $\varepsilon>0$ there exists a compact absolute neighborhood retract that contains $X$ and has the property that each point of the retract is within $\varepsilon$ of $X$. If the choice of $\varepsilon$ is sufficiently large, the retract can be chosen to be an absolute retract.
\end{abstract}

Suppose that $X$ is a compact subset of a Banach space $B$. Then the closure of the convex hull of $X, \overline{\operatorname{conv}(X)}$, is a compact absolute retract that contains $X$. Browder [4] has shown that if $U$ is an open subset of $B$ that contains $X$, then there exists a compact absolute neighborhood retract $R^{*}$ such that $X \subseteq R^{*} \cong U$. Both of these results have proven to be useful in Fixed Point Theory. See, for example, the work of Browder mentioned above and the work of Górniewicz and Granas [9].

Let $X$ be a compact subset of a normed linear space $N$. The purpose of this paper, Theorem 1 , is to show that there exists a compact absolute retract $R$ such that $X \subseteq R \subseteq N$. Further, it is shown that if $U$ is an open subset of $N$ that contains $X$, then there exists a compact absolute neighborhood retract $R^{*}$ such that $X \subseteq R^{*} \leqq U$.

1. Preliminaries. Absolute retracts and absolute neighborhood retracts for metric spaces will be denoted by AR and ANR respectively. We use the notation $d(x, E)(d(x, y))$ for the distance from a point $x$ to a set $E$ (to a point $y$ ). A continuous function $f: X \rightarrow R$ will be called a retraction if $R \subseteq X$ and $f(x)=x$ for each $x \in R$.

Lemma 1. Let $(N,\|\|)$ be an infinite dimensional normed linear space, $X$ be a compact subset of $N, F$ be a finite dimensional subspace that is disjoint from $X$, and $\varepsilon$ be greater than 0 . Then there exists a finite dimensional subspace $E$ that contains $F$, is disjoint from $X$, and for all $x \in X, d(x, E)<\varepsilon$.

Proof Let $U_{*}$ be an open subset of $N$. We show that there exists a finite dimensional subspace $E_{*}$ that contains $F$, meets $U$, and is disjoint from $X$. Let $B$ be the closure of an open set that is contained in $U$ and is disjoint from $X$. For each $b \in B$, let $E_{b}$ be the 
subspace generated by $b$ and $F$. Suppose that for each such $b, E_{b} \cap$ $X \neq \varnothing$. Let $b_{n}$ be an arbitrary sequence in $B$, and let $x_{n} \in E_{b_{n}} \cap X$. Now $b_{n}$ can be expressed in the form $b_{n}=v_{n}+t_{n} x_{n}$ where $v_{n} \in F$ and $t_{n}$ is a real number. The sequences $\left\|v_{n}\right\|$ and $\left|t_{n}\right|$ are bounded, and the sequence $x_{n}$ lies in the compact set $X$. Thus there exist subsequences $v_{n_{k}}, x_{n_{k}}, t_{n_{k}}$, vectors $v \in F, x \in X$ and $t \in R$ such that $b_{n_{k}}=v_{n_{k}}+$ $t_{n_{k}} x_{n_{k}} \rightarrow v+t x$. Since $B$ is closed $v+t x \in B$. This leads us to conclude that $B$ is compact contrary to the fact that $B$ has nonempty interior. Therefore, there exists a subspace $E_{*}$ satisfying the desired properties.

Now cover $X$ with a finite collection of open sets $U_{1}, U_{2}, \cdots, U_{n}$, each with radius less than $\varepsilon / 2$. By applying the result in the above paragraph $n$ times, we are able to construct a finite dimensional subspace $E$ that contains $F$, is disjoint from $X$, and meets each of the $U_{j}$. Let $x \in X$. There exists a $U_{j}$ and a $y \in E$ such that $x, y \in$ $U_{j}$. Then $d(x, E) \leqq d(x, y)<\varepsilon$, and this completes the proof.

Definition 1. [5] Let $(N,\|\|)$ be a normed linear space. Then the norm is said to be strictly convex if for all $x, y$ not equal to 0 , $\|x+y\|=\|x\|+\|y\|$ implies that $y=p x$ for some $p>0$.

Assume that $(N,\|\|)$ is a strictly convex normed linear space and $E$ is a finite dimensional subspace of $N$. It was observed in [2] that for each $x \in N$ there exists a unique closest point, denoted by $\phi(x)$, in $E$. That is, $\phi(x) \in E$ and $d(x, \phi(x))=d(x, E)$. The resulting function $\phi: N \rightarrow E$, which is called a metric projection, has the following properties that are easily verified $[2,12]$.

$\left(\mathscr{P}_{1}\right) \phi$ is continuous,

$\left(\mathscr{P}_{2}\right) \phi$ is idempotent: $\phi^{2}=\phi$,

$\left(\mathscr{P}_{3}\right) \quad \phi$ is homogeneous: $\phi(t x)=t \phi(x)$ for all $t \in R$ and $x \in N$, and

$\left(\mathscr{P}_{4}\right) \quad \phi$ is quasi additive: $\phi(x+y)=\phi(x)+y$ for all $x \in N$ and $y \in E$.

We establish $\mathscr{P}_{1}$. Let $x \in X$ and suppose $x_{n}$ is a sequence that converges to $x$. Without loss of generality we may assume that $\phi\left(x_{n}\right)$ converges to some point $y \in E$. Then $\|x-y\|=\lim _{n \rightarrow \infty}\left\|x-\phi\left(x_{n}\right)\right\|=$ $d(x, E)$. So $y=\phi(x)$, and we conclude that $\phi$ is continuous.

LEMma 2. Let $N$ be a strictly convex normed linear space, $E$ be a finite dimensional subspace of $N, R$ be an absolute neighborhood retract in $E, \phi: N \rightarrow E$ be the metric projection, and e be greater than 0. Then $\phi^{-1}(R)=\{x \in N: \phi(x) \in R\}$ and $\left\{x \in \phi^{-1}(R): d(x, R) \leqq e\right\}$ are absolute neighborhood retracts.

Proof. There exists a neighborhood $U_{*}$ of $R$ in $E$ and a retraction $r_{*}: U_{*} \rightarrow R$. Set $U=\phi^{-1}\left(U_{*}\right)$ and define $r: U \rightarrow \phi^{-1}(R)$ by $r(x)=$ 
$x+r_{*}(\dot{\phi}(x))-\phi(x)$. It follows by properties $\mathscr{P}_{1}$ and $\mathscr{P}_{4}$ that $r$ is a retraction.

Next set $A=\left\{x \in \dot{\phi}^{-1}(R): d(x, R) \leqq e\right\}$ and define $s: \phi^{-1}(R) \rightarrow A$ by

$$
s(x)=\left\{\begin{array}{l}
x \text { if } d(x, R) \leqq e \\
{\left[\frac{d(x, R)-e}{d(x, R)}\right] \phi(x)+\frac{e x}{d(x, R)} \text { if } d(x, R) \geqq e .}
\end{array}\right.
$$

The function $s$ is a retraction. Since a retract of an ANR is an ANR, the proof of the lemma is complete.

2. The approximation theorem. A function $f: X \rightarrow R$ will be called compact retraction provided $f$ is a retraction and $R$ is compact. If $N$ is a normed linear space, and $x \in N$, then $B_{\varepsilon}(x)=\{y \in N: d(x, y) \leqq \varepsilon\}$ is called an $N$-ball. In order to simplify the proof of the approximation theorem, we state the following definition.

Definition 2. Let $K$ be a compact subset of a normed linear space $N$. Then an $\varepsilon$-pair of $K$ in $N$, denoted by $\left(N, K, P^{*}, P, \varepsilon\right)$, consists of ANR's $P^{*}$ and $P$ such that $K \cong \operatorname{Int}\left(P^{*}\right), P^{*} \leqq P \leqq N$ and if $x \in P^{*}, y \in P$ and $d(x, y) \leqq \varepsilon$, then the segment $[x, y]=\{t x+(1-t) y$ : $0 \leqq t \leqq 1\} \subseteq P$.

The proof of the approximation theorem is similar in certain respects to [3, p. 108].

TheOREM. Let $(N,\|\|)$ be a normed space and let $X$ be a compact subset of $N$. Then there exists a compact absolute retract $R$ such that $X \subseteq R \cong N$. If $U$ is an open subset of $N$ that contains $X$, then there exists a compact absolute neighborhood retract $R^{*}$ such that $X \subseteq$ $R^{*} \subseteq U$.

Proof. A straightforward argument establishes the result when the dimension of $N$ is finite. In that which follows we assume that the dimension of $N$ is infinite.

Let $D$ be a countable dense subset of $X$. Then the closure of the linear span of $D$ is a separable normed linear space that contains $X$. Thus, without loss of generality, we may assume that $N$ is separable. Further, we may assume that $X$ does not contain the origin. Every separable normed linear space has an equivalent strictly convex normed [5]. Consequently, we may assume that \| \| is strictly convex.

It will be shown that for $n=1,2,3, \cdots$, there exists

$\left(\mathrm{I}_{n}\right)$ a finite dimensional subspace $E_{n} \supseteq E_{n-1}\left(E_{0}=\varnothing\right)$ with metric projection $\phi_{n}: N \rightarrow E_{n}$ such that if $x \in X$ then $d\left(x, E_{n}\right)<\varepsilon_{n} \leqq \varepsilon_{n-1} / 18$ $\left(\varepsilon_{0}=18\right)$, 
$\left(\mathrm{II}_{n}\right) \quad$ a $3 \varepsilon_{n}$-pair of $\phi_{n}(X)$ in $E_{n},\left(E_{n}, \phi_{n}(X), P_{n}^{*}, P_{n}, 3 \varepsilon_{n}\right)$,

$\left(\mathrm{III}_{n}\right)$ an ANR $A_{n}=\left\{x: x \in \phi_{n}^{-1}\left(P_{n}\right)\right.$ and $\left.d\left(x, P_{n}\right) \leqq 3 \varepsilon_{n}\right\}\left(A_{0}=N\right)$ such that $X \subseteq \operatorname{Int} A_{n}, A_{n} \subseteq \operatorname{Int}\left(A_{n-1}\right)$ and $P_{n-1} \cap A_{n}=\varnothing\left(P_{0}=\varnothing\right)$, and

$\left(\mathrm{IV}_{n}\right)$ a compact retraction $f_{n}: A_{n-1} \rightarrow R_{n}\left(R_{0}=\varnothing, f_{0}=\varnothing\right)$ that satisfies $R_{n} \cap A_{n}=P_{n}, R_{n} \cap R_{n-1}=P_{n-1}, f_{n}(x)=f_{n-1}(x)$ for $x \in b d\left(A_{n-1}\right)$, $f_{n}(x)=\phi_{n}(x)$ for $x \in A_{n}$, and if $x \in A_{n-1}$ and $d\left(x, R_{n}\right) \leqq 3$, then $d\left(x, f_{n}(x)\right) \leqq$ $3 \varepsilon_{n-1}$.

Let $\varepsilon_{1}=1$. By Lemma 1 there exists a finite dimensional subspace $E_{1}$ such that if $x \in X$ then $d\left(x, E_{1}\right)<\varepsilon_{1}$, and $X \cap E_{1}=\varnothing$. Let $\phi_{1}$ : $N \rightarrow E_{1}$ be the corresponding metric projection. There exists a finite number of points $p_{1}^{1}, \cdots, p_{k_{1}}^{1} \in \phi_{1}(X)$ and corresponding $E_{1}$-balls $B_{\varepsilon_{1 / 2}}\left(p_{1}^{1}\right)$, $\cdots, B_{\varepsilon_{1} / 2}\left(p_{k_{1}}^{1}\right)$ such that $\phi_{1}(X) \leqq \operatorname{Int} \bigcup_{i=1}^{k_{1}} B_{\varepsilon_{1} / 2}\left(p_{i}^{1}\right)$.

Set

$$
P_{1}^{*}=\bigcup_{i=1}^{k_{1}} B_{\varepsilon_{1} / 2}\left(p_{i}^{1}\right) \quad \text { and } \quad P_{1}=\left\{x \in E_{1}: d\left(x, P_{1}^{*}\right) \leqq 3 \varepsilon_{1}\right\} .
$$

It is easy to see that $P_{1}^{*}$ and $\mathrm{P}_{1}$ are ANR's [3, p. 90] and it follows that $\left(E_{1}, \phi_{1}(X), P_{1}, P_{1}^{*}, 3 \varepsilon_{1}\right)$ is a $3 \varepsilon_{1}$-pair of $\phi_{1}(X)$ in $E_{1}$. Set $A_{1}=\{x: x \in$ $\dot{\phi}_{1}^{-1}\left(P_{1}\right)$ and $\left.d\left(x, P_{1}\right) \leqq 3 \varepsilon_{1}\right\}$. Clearly, $X \subseteq \operatorname{Int} A_{1}, A_{1} \subseteq N=\operatorname{Int}\left(A_{0}\right)$ and $P_{0} \cap A_{1}=\varnothing \cap A_{1}=\varnothing$. Set $R_{1}=\operatorname{conv}\left(\mathrm{P}_{1}\right)$. There exists a retraction ${ }^{1}$ $s: E_{1} \rightarrow R_{1}$. We define $f_{1}: N \rightarrow R_{1}$ by $f_{1}=s \circ \phi_{1}$. Clearly, $R_{1} \cap A_{1}=P_{1}$, $R_{1} \cap R_{0}=\varnothing=P_{0}, f_{1}(x)=f_{0}(x)$ for $x \in b d\left(A_{0}\right)$ and $f_{1}(x)=\phi_{1}(x)$ for $x \in A_{1}$. Suppose $x \in A_{0}$ and $d\left(x, R_{1}\right) \leqq 3$. Then it is easy to see that $d\left(x, f_{1}(x)\right) \leqq 3 \varepsilon_{0}$. Thus, the four conditions are satisfied for the case $n=1$.

Now assume that for $k=1,2, \cdots, n$ the conditions can be satisfied. We show that for $k=n+1$, there exist appropriate functions and sets that satisfy the conditions.

By condition $\left(\mathrm{III}_{n}\right)$ we have $X \subseteq \operatorname{Int}\left(A_{n}\right)=\left\{x: x \in \phi_{n}^{-1}\left(P_{n}\right)\right.$ and $\left.d\left(x, P_{n}\right) \leqq 3 \varepsilon_{n}\right\}$. There exists an open set $W_{n}$ of $N$ such that $X \leqq$ $W_{n} \subseteq A_{n}, W_{n} \cap P_{n}=\varnothing$, and $\phi_{n}\left(W_{n}\right) \subseteq \operatorname{Int}\left(P_{n}^{*}\right)$. This follows from $\left(\mathrm{II}_{n}\right)$. Let $\varepsilon_{n+1}^{*}=d\left(X, N-W_{n}\right)^{2}$ Set

$$
\varepsilon_{n+1}<\min \left\{\varepsilon_{n} / 18, \varepsilon_{n+1}^{*} / 8\right\} \text {. }
$$

By Lemma 2 there exists a finite dimensional subspace $E_{n+1}$ with metric projection $\phi_{n+1}: N \rightarrow E_{n+1}$ such that if $x \in X$ then $d\left(x, E_{n+1}\right)<$ $\varepsilon_{n+1}, E_{n} \subseteq E_{n+1}$, and $X \cap E_{n+1}=\varnothing$. Thus, condition $\left(\mathrm{I}_{n+1}\right)$ is satisfied.

There exists a finite number of points $p_{1}^{n+1}, p_{2}^{n+1} \cdots p_{k_{n+1}}^{n+1} \in \phi_{n+1}(X)$ and corresponding $E_{n+1}$-balls $B_{\varepsilon_{n+1} / 2}\left(p_{1}^{n+1}\right), \cdots, B_{\varepsilon_{n+1} / 2}\left(p_{k_{n+1}}^{n+1}\right)$ such that $\phi_{n+1}(X) \leqq \operatorname{Int} \bigcup_{i=1}^{k_{n+1}} B_{\varepsilon_{n+1} / 2}\left(p_{i}^{n+1}\right)$. Set

$$
P_{n+1}^{*}=\bigcup_{i=1}^{k_{n+1}} B_{\varepsilon_{n+1} / 2}\left(p_{i}^{n+1}\right) \quad \text { and } \quad P_{n+1}=\left\{x \in E_{n+1}: d\left(x, P_{n+1}^{*}\right) \leqq 3 \varepsilon_{n+1}\right\} .
$$

1 The retraction is constructed in such a manner that $d(x, s(x)) \leqq 2 d\left(x, R_{1}\right)$.

${ }^{2} d\left(X, N-W_{n}\right)=\inf \left\{d\left(x, N-W_{n}\right): x \in X\right\}$ 
It is easy to see that $P_{n+1}^{*}$ and $P_{n+1}$ are ANR's [3, p. 90], and it follows that $\left(E_{n+1}, \phi_{n+1}(X), P_{n+1}^{*}, P_{n+1}, 3 \varepsilon_{n+1}\right)$ is a $3 \varepsilon_{n+1}$-pair of $\phi_{n+1}(X)$ in $E_{n+1}$. Thus condition $\left(\Pi_{n+1}\right)$ is satisfied.

Suppose $x \in P_{n+1}$. Then there exists a $B_{\varepsilon_{n+1} / 2}\left(p_{i}^{n+1}\right)$ and a $y \in$ $B_{\varepsilon_{n+1} / 2}\left(p_{i}^{n+1}\right)$ such that $d(x, y) \leqq 3 \varepsilon_{n+1}$. There exists a $z \in X$ such that $\dot{\phi}_{n+1}(z) \in B_{\varepsilon_{n+1} / 2}\left(p_{i}^{n+1}\right)$. Thus $d(x, z) \leqq d(x, y)+d\left(y, \phi_{n+1}(z)\right)+d\left(\phi_{n+1}(z), z\right)<$ $5 \varepsilon_{n+1}$. We conclude the following:

$$
\text { If } x \in P_{n+1} \text { then } d(x, X)<5 \varepsilon_{n+1} \text {. }
$$

Set $A_{n+1}=\left\{x: x \in \phi_{n+1}^{-1}\left(P_{n+1}\right)\right.$ and $\left.d\left(x, P_{n+1}\right) \leqq 3 \varepsilon_{n+1}\right\}$. By Lemma 2, $A_{n+1}$ is an ANR. We have $\phi_{n+1}(X) \subseteq \operatorname{Int} P_{n+1}^{*}$ and if $x \in X$ then $d\left(x, P_{n}\right)<\varepsilon_{n+1}$. Thus, $X \leqq \operatorname{Int}\left(A_{n+1}\right)$. Let $x \in A_{n+1}$. Then $d\left(x, \phi_{n+1}(x)\right) \leqq$ $3 \varepsilon_{n+1}$ and by $(1) d\left(\phi_{n+1}(x), X\right)<5 \varepsilon_{n+1}$. So $d(x, X)<8 \varepsilon_{n+1}<\varepsilon_{n+1}^{*}$. Thus, $x \in W_{n}$ and it follows, from the fact that $A_{n+1} \subseteq W_{n} \subseteq \operatorname{Int} A_{n}$, that $A_{n+1} \subseteq \operatorname{Int} A_{n}$. By construction $P_{n} \cap A_{n+1}=\varnothing$. Condition ( III $\left._{n+1}\right)$ is satisfied. We also note that $\phi_{n}\left(P_{n+1}\right) \subseteq P_{n}^{*}$. This follows since $P_{n+1} \subseteq W_{n}$.

We set $B_{n+1}=\left\{x: x \in E_{n+1} \cap \phi_{n}^{-1}\left(P_{n}^{*}\right)\right.$ and $\left.d\left(x, P_{n}^{*}\right) \leqq(23 / 18) \varepsilon_{n}\right\}$. Suppose $x \in P_{n+1}$. Then $x \in E_{n+1}$. Also, $d\left(x, P_{n}^{*}\right) \leqq d(x, X)+\varepsilon_{n}$. By (1) and the definitions of $P_{n}^{*}$ and $\varepsilon_{n+1}$, we have $d\left(x, P_{n}^{*}\right) \leqq 5 \varepsilon_{n+1}+\varepsilon_{n} \leqq$ $(23 / 18) \varepsilon_{n}$. We conclude that $P_{n+1} \subseteq B_{n+1}$. By Lemma 2 and the fact that $E_{n+1}$ is finite dimensional, we have that $B_{n+1}$ is a compact ANR. Furthermore, it is clear that $B_{n+1} \subseteq \operatorname{Int}\left(A_{n}\right)$. We defined

$$
R_{n+1}^{*}=P_{n} \cup B_{n+1} \cup A_{n+1} .
$$

It is clear that $R_{n+1}^{*}$ is a closed subspace of $A_{n}$ and by [3, p. 90] $R_{n+1}$ is an ANR. So there exists an open subset $U_{n+1}^{*}$ of $R_{n+1}$ in $A_{n}$ and a retraction $r_{n+1}: U_{n+1}^{*} \rightarrow R_{n+1}^{*}$. For each $x \in A_{n+1} \cup B_{n+1}$ there exists a pair of neighborhoods $M_{x}^{n+1}, N_{x}^{n+1}$ such that $\operatorname{dia}\left(M_{x}^{n+1}\right)<\varepsilon_{n+1} / 2$, $\operatorname{dia} \phi_{n}\left(M_{x}^{n+1}\right)<\varepsilon_{n+1}, N_{x}^{n+1} \cong M_{x}^{n+1} \subseteq U_{n+1}^{*}$ and $r_{n+1}\left(N_{x}^{n+1}\right) \subseteq M_{x}^{n+1}$. Set

$$
U_{n+1}=\bigcup\left\{N_{x}^{n+1}: x \in A_{n+1} \cup B_{n+1}\right\} \text {. }
$$

Now suppose $x \in U_{n+1}$. Then it is easy to see that $\phi_{n}\left(\phi_{n+1}\left(r_{n+1}(x)\right)\right) \in$ $P_{n}$. We argue that the segment $\left[\phi_{n}\left(\phi_{n+1}\left(r_{n+1}(x)\right)\right), \phi_{n}(x)\right] \subseteq P_{n}$. Assume $r_{n+1}(x) \in A_{n+1}$. Then there exists an $M_{y}$ such that $x, r_{n+1}(x) \in M_{y}$. Since $\operatorname{dia}\left(M_{y}\right)<\varepsilon_{n+1} / 2, d\left(x, r_{n+1}(x)\right)<\varepsilon_{n+1}$. By the definition of $A_{n+1}$ it follows that $d\left(\phi_{n+1}\left(r_{n+1}(x)\right), r_{n+1}(x)\right)<3 \varepsilon_{n+1}$. By (1) $d\left(\phi_{n+1}\left(r_{n+1}(x)\right), X\right)<$ $5 \varepsilon_{n+1}$. From condition $\left(\mathrm{I}_{n}\right)$, we conclude that if $z \in X$ then $d\left(z, P_{n}\right)<$ $\varepsilon_{n}$. Combining the above we get

$$
\begin{aligned}
d\left(x, \phi_{n}\left(\phi_{n+1}\left(r_{n+1}(x)\right)\right)\right) \leqq & d\left(x, r_{n+1}(x)\right)+d\left(r_{n+1}(x), \phi_{n+1}\left(r_{n+1}(x)\right)\right) \\
& +d\left(\phi_{n+1}\left(r_{n+1}(x)\right), X\right)+\varepsilon_{n}<9 \varepsilon_{n+1}+\varepsilon_{n} .
\end{aligned}
$$

Thus, $d\left(x, \phi_{n}(x)\right) \leqq 9 \varepsilon_{n+1}+\varepsilon_{n}$ and 


$$
d\left(\phi_{n}\left(\phi_{n+1}\left(r_{n+1}(x)\right)\right), \phi_{n}(x)\right) \leqq 18 \varepsilon_{n+1}+2 \varepsilon_{n}<3 \varepsilon_{n} .
$$

By $\left(\mathrm{II}_{n}\right)$ the segment $\left[\phi_{n}\left(\phi_{n+1}\left(r_{n+1}(x)\right)\right), \phi_{n}(x)\right] \subseteq P_{n}$. Suppose $r_{n+1}(x) €$ $B_{n+1}$. As in the case above, $d\left(x, r_{n+1}(x)\right)<\varepsilon_{n+1}$. Note that in this case $r_{n+1}(x)=\phi_{n+1}\left(r_{n+1}(x)\right)$. By the definition of $B_{n+1}, d\left(\phi_{n+1}\left(r_{n+1}(x)\right)\right.$, $\phi_{n}\left(\phi_{n+1}\left(r_{n+1}(x)\right)\right) \leqq(23 / 18) \varepsilon_{n}$. So

$$
\begin{aligned}
d\left(x, \phi_{n}\left(\phi_{n+1}\left(r_{n+1}(x)\right)\right)\right) & \leqq d\left(x, r_{n+1}(x)\right)+d\left(\phi_{n+1}\left(r_{n+1}(x)\right), \phi_{n}\left(\phi_{n+1}\left(r_{n+1}(x)\right)\right)\right) \\
& <\varepsilon_{n+1}+\frac{23}{18} \varepsilon_{n} .
\end{aligned}
$$

Thus, $d\left(x, \phi_{n}(x)\right) \leqq \varepsilon_{n+1}+(23 / 18) \varepsilon_{n}$ and

$$
d\left(\phi_{n}\left(\phi_{n+1}\left(r_{n+1}(x)\right)\right), \phi_{n}(x)\right) \leqq 2 \varepsilon_{n+1}+\frac{23}{9} \varepsilon_{n}<\frac{24}{9} \varepsilon_{n}<3 \varepsilon_{n} .
$$

Thus, by $\left(\mathrm{II}_{n}\right)$ the segment $\left[\phi_{n}\left(\phi_{n+1}\left(r_{n+1}(x)\right)\right), \phi_{n}(x)\right] \subseteq P_{n}$. Finally, suppose $r_{n+1}(x) \in P_{n}$. As in the cases above, $d\left(x, r_{n+1}(x)\right)<\varepsilon_{n+1}$. Since $r_{n+1}(x) \in$ $P_{n}, d\left(x, E_{n}\right) \leqq \varepsilon_{n+1}$. Thus, $d\left(r_{n+1}(x), \phi_{n}(x)\right)<2 \varepsilon_{n+1}$. But in this case $r_{n+1}(x)=\phi_{n}\left(\phi_{n+1}\left(r_{n+1}(x)\right)\right)$. So $d\left(\phi_{n}\left(\phi_{n+1}\left(r_{n+1}(x)\right)\right), \phi_{n}(x)\right)<2 \varepsilon_{n+1}<3 \varepsilon_{n}$. We also conclude in this final case that the segment $\left[\phi_{n}\left(\phi_{n+1}\left(r_{n+1}(x)\right)\right)\right.$, $\left.\phi_{n}(x)\right] \subseteq P_{n}$.

Set $R_{n+1}=P_{n} \cup B_{n+1}$. For each $x \in U_{n+1}$ define $a_{n+1}(x)=d\left(x, A_{n+1} \cup\right.$ $\left.B_{n+1}\right)$ and $b_{n+1}(x)=d\left(x, A_{n}-U_{n}\right)$. We define

$$
f_{n+1}: A_{n} \longrightarrow R_{n+1}
$$

by

$$
\begin{aligned}
& \left(\begin{array}{l}
\phi_{n}(x) \text { if } x \in A_{n}-U_{n+1} \\
\frac{b_{n+1}(x)\left(\phi_{n}\left(\phi_{n+1}\left(r_{n+1}(x)\right)\right)\right)+\left(a_{n+1}(x)-b_{n+1}(x)\right) \phi_{n}(x)}{a_{n+1}(x)}
\end{array}\right. \\
& f_{n+1}(x)=\left\{\begin{array}{c}
a_{n+1}(x) \geqq b_{n+1}(x) \\
\frac{a_{n+1}(x)\left(\phi_{n}\left(\phi_{n+1}\left(r_{n+1}(x)\right)\right)\right)+\left(b_{n+1}(x)-a_{n+1}(x)\right) \phi_{n+1}\left(r_{n+1}(x)\right)}{b_{n+1}(x)} \text { if }
\end{array}\right. \\
& a_{n+1}(x) \leqq b_{n+1}(x), \\
& { }_{\phi_{n+1}}(x): x \in A_{n+1} \text {. }
\end{aligned}
$$

By $\mathscr{P}_{3}$ and $\mathscr{P}_{4}$ we have that if $x \in B_{n+1}$, then the segment $\left[x, \phi_{n}(x)\right] \subseteq B_{n+1}$. It follows that $f_{n+1}$ is a compact retraction from $A_{n}$ to $R_{n+1}, R_{n+1} \cap A_{n+1}=P_{n+1}, R_{n+1} \cap R_{n}=P_{n}, f_{n+1}(x)=f_{n}(x)$ for $x \in b d\left(A_{n}\right)$ and $f_{n+1}(x)=\phi_{n+1}(x)$ for $x \in A_{n+1}$. It is easy to see that if $x \in A_{n}$, then $d\left(x, R_{n+1}\right) \leqq 3$ and $d\left(x, f_{n+1}(x)\right) \leqq 3 \varepsilon_{n}$.

We have satisfied the conditions for $k=n+1$; thus, the conditions can be satisfied for all $k$. Set $R=\bigcup_{n=1}^{\infty}\left(R_{n}\right) \cup X$.

We define $f: N \rightarrow R$ by 


$$
f(x)=\left\{\begin{array}{lll}
x: & \text { if } & x \in X \\
f_{n}(x): & \text { if } & x \in A_{n-1}-A_{n} .
\end{array}\right.
$$

It is clear that $f$ is a continuous function for all $x \notin X$. Now suppose $x \in X$ and let $\varepsilon>0$. By $\left(\mathrm{I}_{n}\right)$, there exists an $M$ such that if $n \geqq M$ then $3 \varepsilon_{n}<\varepsilon / 2$. Choose a neighborhood $N_{x}$ of diameter $<\varepsilon / 2$ about $x$ in $A_{M}$. Then if $y \in N_{x}, d(f(y), y)<3 \varepsilon_{M}<\varepsilon / 2$ and $d(y, x)<\varepsilon / 2$. Thus, $d(f(x), f(y))<\varepsilon$ and we conclude that $f$ is continuous at $x$. It is easy to see that $R$ is compact and $f(x)=x$ for each $x \in R$. Thus, $f: N \rightarrow R$ is a compact retraction. The space $R$ is the desired $\mathrm{AR}$.

Let $U$ be an open set that contains $X$. Then there exists an $n$ such that $A_{n}$ is a closed subset of $U$. Now $A_{n}$ is an absolute neighborhood retract for metric spaces. So there exists an open set $V$ of $U$ that contains $A_{n}$ and a retraction $r: V \rightarrow A_{n}$. Then $f \mid A_{n} \circ r$ is the desired retraction, and $R^{*}=f\left(A_{n}\right)$ is the desired ANR.

3. Applications. In this section, Theorem 1 will be used to establish a number of results.

The following extension theorem is due to Dugundji and Granas [7].

THEOREM 2. Let $A$ be a closed subset of a normal space $X$ and let $N$ be a normed linear space. Suppose that $f: A \rightarrow N$ is a continuous mapping such that $\overline{f(A)}$ is compact. Then there exists an extension, $F: X \rightarrow N$, of $f$ such that $\overline{f(X)}$ is compact.

Proof. The Dugundji extension theorem [6] assures that $f$ has an extension $F^{*}: X \rightarrow N$. Theorem 1 implies that there exists a compact $\mathrm{AR} R$ such that $\overline{f(A)} \cong R$. There exists a retraction $r: N \rightarrow$ $R$. The composition $r \circ F^{*}=F$ is the desired extension.

THeorem 3. [11] Let $X$ be an $\mathrm{AR}$ and let $f: X \rightarrow X$ be a continuous function such that $\overline{f(X)}$ is compact. Then $f$ has a fixed point.

Proof. By the Arens-Eells embedding theorem [1], $X$ can be realized as a closed subset of a normed linear space $N$.

There exists a retraction $r: N \rightarrow X$ from $N$ to $X$. By Theorem 1 there exists a compact AR $R$ such that $f(X) \subseteq R$. Set $g=f \circ r \mid R$. Since every compact AR has the fixed point property, the function $g: R \rightarrow R$ has a fixed point $x$. Thus, $x=g(x)=f(r(x))=f(x)$. So $f$ has a fixed point. 
The Čech homology groups and the singular homology groups of a compact AR are isomorphic [13, p. 145]. Theorem 1 implies that in the class of compact subsets of an open subset of a normed linear space the compact AR's are cofinal. Thus we have the following theorem.

THEOREM $4^{3}$. The Čech homology groups with compact support and the singular homology groups of an open subset of a normed linear space are isomorphic.

A multi-valued upper semi-continuous mapping $\phi: X \rightarrow Y$ is said to be admissible if for each $x \in X, \phi(x)$ is compact and acyclic $[8,9]$. The following theorem, which is a generalization of Theorem 2 , is an important special case of the principal result of [8].

TheOREM 5. Let $X$ be an ANR and let $\phi: X \rightarrow X$ be an admissible map such that $\overline{\phi(X)}$ is compact. Then the Lefschetz number of $\phi$, $\Lambda \phi$, can be defined, and $\Lambda \phi \neq 0$ implies that there exists an $x \in X$ such that $x \in \phi(x)$.

Proof. Górniewicz and Granas [9] prove this result for the case that $X$ is a topologically complete ANR. Their argument carries over to the incomplete case if Lemma 9.1 of [9] is replaced by Theorem 1.

The following theorem, which is a special case of $[4.4, \mathrm{p} .95,10]$ follows from Theorem 1 and Theorem 11 of [4].

Theorem 6. Let $X$ be an AR and $f: X \rightarrow X$ be a continuous and locally compact mapping from $X$ to $X$. If for some positive integer $n, \overline{f^{n}(X)}$ is compact, then $f$ has a fixed point.

\section{REFERENCES}

1. R. F. Arens and J. Eells, Jr., On embedding uniform and topological spaces, Pacific

J. Math., 6 (1956), 397-403.

2. N. Aronszajn and K. T. Smith, Invariant subspaces of completely continuous operators, Annals of Math., 2 (1960), 345-380.

3. K. Borsuk, Theory of retracts, Monografie Matematyczne, vol. 44, Warszawa, (1967).

4. F. Browder, Fixed point theorems on infinite dimensional manifolds, Trans. Amer. Math. Soc., (1965), 179-193.

5. J. A. Clarkson, Uniformly convex spaces, Trans. Amer. Math. Soc., (1936), 396-414.

6. J. Dugundji, An extension of Tietze's theorem, Pacific J. Math., 1 (1951), 353-367.

${ }^{3}$ I would like to exprass my appreciation to L. Gorniewicz for pointing out the application. 
7. J. Dugundji and A. Granas, Fixed point theory, vol. 1, to appear.

8. L. Górniewicz, Homological methods in fixed-point theory of mnlti-valued maps, Dissertationes Mathematicae, 129 (1976).

9. L. Górniewicz and A. Granas, Fixed point theorems for multi-valued mappings of the absolute neighborhood retracts, J. de Math, Pure et Appl., 49 (1970), 381-395.

10. A. Granas, Points Fixes pour Les Applications Compactes: Espaces de Lefschetz et la Thé́rie de L'Indice, Les Presses de L'Université de Montréal, 1980.

11. - Topics in infinite dimensional topology, Séminaire Jean Leray, Collège de France (1969-1970).

12. R. Holmes, Geometric Functional Analysis and its Applications, Springer-Verlag, 1975.

13. S. T. Hu, Theory of Retracts, Wayne State Univ. Press, 1965.

Received September 3, 1980.

California Polytechnic State University

SAN LUIS OBISPo, CA 93407 



\title{
PACIFIC JOURNAL OF MATHEMATICS
}

\section{EDITORS}

\author{
DONALD BABBITT (Managing Editor) \\ University of California \\ Los Angeles, CA 90024 \\ Hugo RossI \\ University of Utah \\ Salt Lake City, UT 84112 \\ C. C. Moore and ANDrew OGG \\ University of California \\ Berkeley, CA 94720
}

\section{J. DugundjI}

Department of Mathematics

University of Southern California

Los Angeles, CA 90007

R. FinN and J. Milgram

Stanford University

Stanford, CA 94305

\section{ASSOCIATE EDITORS}
R. ARENS
E. F. BeCKENBACH
B. H. NeUMANN
F. WOLF
K. YoshidA

\section{SUPPORTING INSTITUTIONS}

UNIVERSITY OF ARIZONA

UNIVERSITY OF BRITISH COLUMBIA

CALIFORNIA INSTITUTE OF TECHNOLOGY

UNIVERSITY OF CALIFORNIA

MONTANA STATE UNIVERSITY

UNIVERSITY OF NEVADA, RENO

NEW MEXICO STATE UNIVERSITY

OREGON STATE UNIVERSITY

\author{
UNIVERSITY OF OREGON \\ UNIVERSITY OF SOUTHERN CALIFORNIA \\ STANFORD UNIVERSITY \\ UNIVERSITY OF HAWAII \\ UNIVERSITY OF TOKYO \\ UNIVERSITY OF UTAH \\ WASHINGTON STATE UNIVERSITY \\ UNIVERSITY OF WASHINGTON
}

The Supporting Institutions listed above contribute to the cost of publication of this Journal, but they are not owners or publishers and have no responsibility for its content or policies.

Mathematical papers intended for publication in the Pacific Journal of Mathematics should be in typed form or offset-reproduced, (not dittoed), double spaced with large margins. Please do not use built up fractions in the text of the manuscript. However, you may use them in the displayed equations. Underline Greek letters in red, German in green, and script in blue. The first paragraph or two must be capable of being used separately as a synopsis of the entire paper. Please propose a heading for the odd numbered pages of less than 35 characters. Manuscripts, in triplicate, may be sent to any one of the editors. Please classify according to the scheme of Math. Reviews, Index to Vol. 39. Supply name and address of author to whom proofs should be sent. All other communications should be addressed to the managing editor, or Elaine Barth, University of California, Los Angeles, California, 90024.

50 reprints to each author are provided free for each article, only if page charges have been substantially paid. Additional copies may be obtained at cost in multiples of 50 .

The Pacific Journal of Mathematics is issued monthly as of January 1966. Regular subscription rate: $\$ 102.00$ a year (6 Vols., 12 issues). Special rate: $\$ 51.00$ a year to individual members of supporting institutions.

Subscriptions, orders for numbers issued in the last three calendar years, and changes of address shoud be sent to Pacific Journal of Mathematics, P.O. Box 969, Carmel Valley, CA 93924, U.S.A. Old back numbers obtainable from Kraus Periodicals Co., Route 100, Millwood, NY 10546.

PUBLISHED BY PACIFIC JOURNAL OF MATHEMATICS, A NON-PROFIT CORPORATION

Printed at Kokusai Bunken Insatsusha (International Academic Printing Co., Ltd.). 8-8, 3-chome, Takadanobaba, Shinjuku-ku, Tokyo 160, Japan. 


\section{Pacific Journal of Mathematics}

\section{Vol. 98, No. 1 \\ March, 1982}

Humberto Raul Alagia, Cartan subalgebras of Banach-Lie algebras of

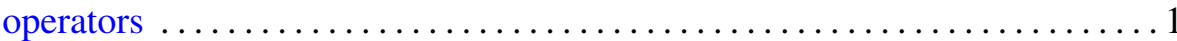

Tom M. (Mike) Apostol and Thiennu H. Vu, Elementary proofs of

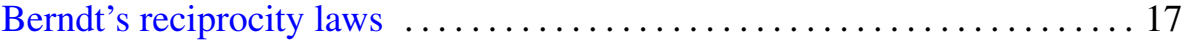

James Robert Boone, A note on linearly ordered net spaces $\ldots \ldots \ldots \ldots . \ldots 25$

Miriam Cohen, A Morita context related to finite automorphism groups of

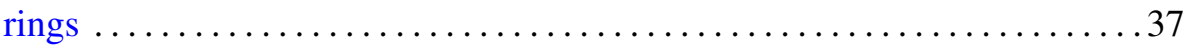

Willibald Doeringer, Exceptional values of differential polynomials . . . . . . 55

Alan Stewart Dow and Ortwin Joachim Martin Forster, Absolute

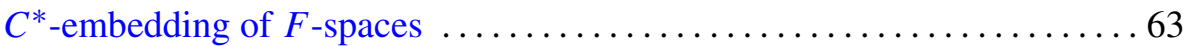

Patrick Hudson Flinn, A characterization of $M$-ideals in $B\left(l_{p}\right)$ for

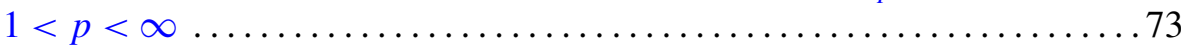

Jack Emile Girolo, Approximating compact sets in normed linear spaces . . . 81

Antonio Granata, A geometric characterization of $n$th order convex

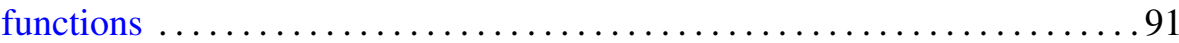

Kenneth Richard Johnson, A reciprocity law for Ramanujan sums . . . . . . .99

Grigori Abramovich Kolesnik, On the order of $\zeta\left(\frac{1}{2}+i t\right)$ and $\Delta(R) \ldots \ldots 107$

Daniel Joseph Madden and William Yslas Vélez, Polynomials that

represent quadratic residues at primitive roots $\ldots \ldots \ldots \ldots \ldots \ldots \ldots 123$

Ernest A. Michael, On maps related to $\sigma$-locally finite and $\sigma$-discrete

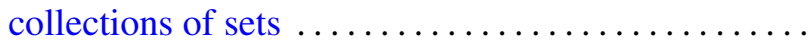

Jean-Pierre Rosay, Un exemple d'ouvert borné de $\mathbf{C}^{3}$ “taut" mais non

hyperbolique complet

Roger Sherwood Schlafly, Universal connections: the local problem

Russel A. Smucker, Quasidiagonal weighted shifts .....

Eduardo Daniel Sontag, Remarks on piecewise-linear algebra . .

Jan Søreng, Symmetric shift registers. II

H. M. (Hari Mohan) Srivastava, Some biorthogonal polynomials suggested

by the Laguerre polynomials 